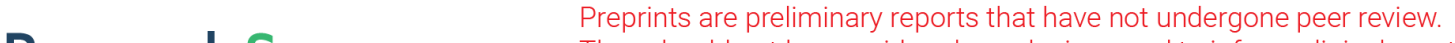 They should not be considered conclusive, used to inform clinical practice, or referenced by the media as validated information. \\ Fabrication of Mechanically Enhanced Hydroxyapatite Scaffold With the Assistance of Numerical Analysis
}

Johnson Kehinde Abifarin ( $\square$ abifarinjohnsonk@yahoo.com )

Ahmadu Bello University

Muhammad Uhuotu Suleiman

Ahmadu Bello University

Emmanuel Alaba Abifarin

Ahmadu Bello University

Fredah Batale Fidelis

Ahmadu Bello University

Opeyemi Kolawole Oyelakin

Ahmadu Bello University

David Ifeakachukwu Jacob

Ahmadu Bello University

Moshood Yemi Abdulrahim

Ahmadu Bello University

\section{Research Article}

Keywords: Processing parameters, optimization, hydroxyapatite, mechanical characteristics, Grey relational analysis

Posted Date: July 20th, 2021

DOI: https://doi.org/10.21203/rs.3.rs-717243/v1

License: (9) This work is licensed under a Creative Commons Attribution 4.0 International License. Read Full License

Version of Record: A version of this preprint was published at The International Journal of Advanced Manufacturing Technology on October 13th, 2021. See the published version at https://doi.org/10.1007/s00170-021-08184-y. 


\title{
Fabrication of mechanically enhanced hydroxyapatite scaffold with the assistance of numerical analysis
}

\author{
Johnson Kehinde Abifarin ${ }^{a^{*}}$, Muhammad Uhuotu Suleiman ${ }^{\mathrm{b}}$, Emmanuel Alaba Abifarinc, Fredah \\ Batale Fidelis $^{\mathrm{b}}$, Opeyemi Kolawole Oyelakin ${ }^{\text {, }}$ David Ifeakachukwu Jacob $\&$ Moshood Yemi \\ Abdulrahim ${ }^{\mathrm{a}}$

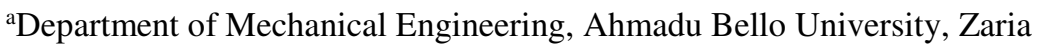 \\ bepartment of Metallurgical and Materials Engineering, Ahmadu Bello University, Zaria \\ ${ }^{\mathrm{c} F a c u l t y ~ o f ~ P h a r m a c e u t i c a l ~ S c i e n c e s, ~ A h m a d u ~ B e l l o ~ U n i v e r s i t y, ~ Z a r i a ~}$ \\ ${ }^{\mathrm{d}}$ Department of Leather Technology, Nigerian Institute of Leather and Science Technology, Samaru Zaria \\ ${ }^{\mathrm{e}} \mathrm{GZ}$ Industries Limited Agbara Lagos State Nigeria \\ *jkabifarin@abu.edu.ng
}

\begin{abstract}
Hydroxyapatite (HAp) has been found to be incompetent as it relates to its mechanical integrity, which somewhat restricts its use for load bearing clinical applications. In this study, synthesis and Taguchi grey relational analysis were conducted in the fabrication of mechanically enhanced HAp scaffold for load bearing application. The XRD and FTIR of raw cow bones (RB) and HAp sintered at 900,1000 , and $1100{ }^{\circ} \mathrm{C}$ show calcium phosphate contents of the bulk materials. It was also observed that increase in sintering temperature made prominent characteristic peaks of HAp phase to become narrower on the XRD patterns. Taguchi design analysis on the individual hardness and compressive strength revealed $1100{ }^{\circ} \mathrm{C}$ as the optimal sintering temperature, but a disparity in compaction load displaying $5 \mathrm{KN}$ for high hardness and $15 \mathrm{~K}$ for high compressive strength. Conversely, Taguchi-grey relational analysis gave a common optimal processing parameter levels for high hardness and compressive strength to produce mechanically enhanced HAp scaffold, and are $1100{ }^{\circ} \mathrm{C}$ sintering temperature and $5 \mathrm{KN}$ compaction load. Significantly, this study revealed that compaction load has a very high percentage of contribution of $90.15 \%$ compared to sintering temperature having a contribution of $7.79 \%$. Confirmation analysis also proved that the experimental grey relational grade of 0.7824 is within $95 \%$ confidence interval.
\end{abstract}

Keywords: Processing parameters; optimization; hydroxyapatite; mechanical characteristics; Grey relational analysis

\subsection{Introduction}

Hydroxyapatite (HAp) of biowastes (coral-, bovine- or marine algae derived) or from synthetic source is commercially available for use in bone repair, substitution and augmentation and as scaffolds in tissue engineering for bone regeneration. HAp is also used as abrasives to roughen 
metal implant surfaces and as source material for depositing bioactive coatings on orthopedic and dental implants. These materials can also be used as transfection agents, drug carriers and percutaneous devices. HAp has been found to be disadvantaged as it relates to its mechanical integrity which somewhat restricts its use for load bearing clinical applications. Therefore, extensive studies are geared towards methods that have the potential of enhancing the mechanical properties of HAp without overly compromising its bio-compatibility. These methods stem from tailoring the processing of the HAp powders, carefully optimizing the sintering temperature and its scaffold compaction loading (Niakan et al., 2015; Adeogun et al., 2018; Abifarin, 2021).

The Taguchi strategy includes diminishing the variety in a cycle through hearty plan of tests. The general target of the strategy is to deliver top notch product for minimal expense to the producer. The Taguchi strategy was created by Dr. Genichi Taguchi of Japan who kept up that variety. Taguchi fostered a technique for planning analyses to explore what various boundaries mean for the mean and change of a cycle execution trademark that characterizes how well the interaction is working. The test configuration proposed by Taguchi includes utilizing symmetrical clusters to put together the boundaries influencing the cycle and the levels at which they ought to be shifts. Rather than testing all potential blends like the factorial plan, the Taguchi technique tests sets of mixes. This takes into consideration the getting of data to figure out which factors most influence product quality with a base measure of experimentation, thereby saving time and resources. Grey relational analysis (GRA) is a numerical analysis to optimize more than one performance characteristics of a system, processes or materials, with the assistance of singular optimization (Kilickap et al., 2017; Puh et al., 2016; Awodi et al., 2021). GRA convert composite responses to a singular response that can be recognized by optimization software.

In this study, synthesis and numerical analysis technique in the fabrication of mechanically enhanced HAp scaffold for load bearing application has been reported. Taguchi grey relational analysis is a numerical analysis that is capable of identifying the best combination of HAp processing parameter levels to fabricate mechanically enhanced HAp scaffold suitable for load bearing and biomedical application.

\subsection{Materials and Methods}

\subsection{Hydroxyapatite synthesis and sintering}

Raw cow bones (RB) were collected from an Abattoir in Zaria, Nigeria, and were used as a source to produce hydroxyapatite. The collected raw bones were first fired with charcoal to remove the bones protein, collagen, and some organic components until no smoke was observed. The carbonization was done to avoid build-up smokes and pressure within the closed furnace. The carbonized bones were further taken into the an electric furnace for complete calcination at $900{ }^{\circ} \mathrm{C}$ at a ramp rate of $5{ }^{\circ} \mathrm{C} / \mathrm{min}$ with $2 \mathrm{~h}$ of soaking time and allowed to furnace cool. The raw bones and the calcined sample were analysed with XRD and FTIR machines. Next, the calcined sample was crushed with a metallic mortar and pestle and sieved through a $300 \mu \mathrm{m}$ mesh sieve to obtain a fine powder. The powdery sample was cold-compacted in cylindrical shape $(25 \mathrm{~mm}$ 
diameter and $10 \mathrm{~mm}$ thickness) under 5, 10, and $15 \mathrm{KN}$ with Universal testing machine (UTM). The fabricated scaffolds were sintered at 900,1000 and $1100{ }^{\circ} \mathrm{C}$ for $2 \mathrm{~h}$ at the heating rate of 5 ${ }^{\circ} \mathrm{C} / \mathrm{min}$. The sintered scaffolds were analysed with XRD and FTIR machines to know the phase structure and the functional groups characteristics.

\subsection{Mechanical measurement}

The micro hardness (HV) of the sintered scaffolds was investigated via the Vickers indentation with a MHV10002 micro hardness tester. The scaffolds were subjected to an applied load of 300 $\mathrm{g}$ for a dwell time of $10 \mathrm{~s}$. A total of 5 indentations were made on each scaffold resulting to 5 hardness values for accuracy. The compressive strength of the scaffolds was performed using a universal testing machine (UTM), equipped with a $5 \mathrm{kN}$ load cell. 5 scaffolds were analyzed for each condition for accuracy.

\subsection{Experimental design}

According to the described processing procedures in section 2.1, mechanical properties of HA scaffolds were evaluated with the consideration of two processing parameters, namely, sintering temperature and compaction load, each at three levels as show in Table 1a.

Table 1a: Processing parameters of mechanical properties and their levels

\begin{tabular}{lll}
\hline Processing parameters & Sintering temperature $\left({ }^{\circ} \mathrm{C}\right)$ & Compaction load $(\mathrm{KN})$ \\
\hline Level 1 & 900 & 5 \\
Level 2 & 1000 & 10 \\
Level 3 & 1100 & 15 \\
\hline
\end{tabular}

A Taguchi L9 orthogonal array (OA) was employed with nine runs for the experiments as shown in Table 1b. The mechanical characteristics were assessed using two response variables, namely, hardness and compressive strength (see section 2.2).

Table 1b: Experimental design strategy

\begin{tabular}{lll}
\hline Experimental runs & Sintering temperature $\left({ }^{\circ} \mathrm{C}\right)$ & Compaction load $(\mathrm{KN})$ \\
\hline 1 & 900 & 5 \\
2 & 900 & 10 \\
3 & 900 & 15 \\
4 & 1000 & 5 \\
5 & 1000 & 10 \\
6 & 1000 & 15 \\
7 & 1100 & 5 \\
8 & 1100 & 10 \\
9 & 1100 & 15 \\
\hline
\end{tabular}

2.4 Signal to noise $(\mathrm{S} / \mathrm{N})$ ratios in the Taguchi design method 
The orthogonal arrays were employed in Taguchi method to minimize variance and optimize process parameters. The $\mathrm{S} / \mathrm{N}$ ratio is used in Taguchi method as a performance characteristic to measure the strength of process and to evaluate the extent of deviation from the desired values (Puh et al., 2016). In calculating the $\mathrm{S} / \mathrm{N}$ ratio, a logarithmic function is computed by assessing the proportion of signal (mean) to the noise (standard deviation) (Pervez et al., 2018). Higher values of $\mathrm{S} / \mathrm{N}$ ratios are preferred to minimize noise and the effects of uncontrollable factors (Prasanth \& Ramesh, 2017). High S/N ratios indicate better-quality of a product. The higher-thebetter, $\mathrm{S} / \mathrm{N}$ ratio type was chosen because a higher hardness and compressive strength is desired, and it is shown in equation 1 (Achuthamenon et al., 2018).

$\frac{S}{N}_{H T B}=-10 \times \log _{10}\left(\frac{1}{n} \sum_{i=1}^{n} \frac{1}{y_{i}{ }^{2}}\right)$

Where $\mathrm{n}$ is the experimental number, $\mathrm{y}_{\mathrm{i}}$ symbolizes the response value of the ith experiment in the OA.

\subsection{Multi-mechanical characteristic optimization using GRA}

Taguchi DOE method is sufficient to evaluate the optimal processing parameters for a single mechanical characteristic. In the situation of two or more mechanical characteristics, with different quality characteristics, multi-mechanical characteristic optimization using GRA is the chosen method. When there is seemingly irregular finite data to be determined, grey analysis can also be employed data (Zhang et al., 2017). Hence, multi-mechanical characteristic (hardness and compressive strength) optimization of processing parameters in this study is conducted using the subsequent steps in GRA.

\subsubsection{Grey relational generation}

In data analysis with GRA, the function of the processing parameters is neglected when there is a high standard value and a high reference sequence range. In addition, if there is dissimilar goal compared with the directions of processing parameters, GRA may yield inexact results. Therefore, pre-processing of data is done to normalize the original reference sequences to a comparable sequence within the range of zero to one (Manoharan et al., 2017; Lin, 2004; Prasanth et al., 2018; Abifarin, 2021). Normalizing of data into a group of sequences is referred to as grey relational generation. The data in this study was normalized using the larger-the-better as shown in equation 2 :

$x_{i}(k)=\frac{y_{i}(k)-\min y_{i}(k)}{\max y_{i}(k)-\min y_{i}(k)}$

Where $\mathrm{x}_{\mathrm{i}}(\mathrm{k})$ is the normalized data for the ith experiment, and $\mathrm{y}_{\mathrm{i}}(\mathrm{k})$ denotes the initial sequence of the mean of the responses

2.5.1 Grey relational coefficient and grade computation

After normalizing the sequence, the next step is to compute the deviation sequence of the reference sequence as shown in equation 3 : 
$\Delta_{o i}(k)=\left\|\mathrm{x}_{\mathrm{o}}(\mathrm{k})-\mathrm{x}_{\mathrm{i}}(\mathrm{k})\right\|$

Where $\Delta_{o i}(k), \mathrm{x}_{0}(\mathrm{k})$, and $\mathrm{x}_{\mathrm{i}}(\mathrm{k})$ are the deviation, reference and comparability sequences respectively. Next, the grey relational coefficient (GRC) is computed using equation (4):

$\xi_{i}(k)=\frac{\Delta_{\min }+\zeta \Delta_{\max }}{\Delta_{o i}(k)+\zeta \Delta_{\max }}$

Where $\xi_{i}(k)$ symbolizes GRC of individual response variables calculated as a function of $\Delta_{\min }$ and $\Delta_{\max }$, the minimum and the maximum deviations of each response variable. $\zeta$ is the distinguishing coefficient $(0 \sim 1)$, but its equal weight of 0.5 is usually assign to each parameter. As reflected in equation 5, grey relational grade (GRG) is then calculated by averaging the GRC of each response variable:

$\gamma_{i}=\frac{1}{n} \sum_{i=1}^{n} \xi_{i}(k)$

Where $\gamma_{i}=$ the value of GRG determined for the ith experiment, $\mathrm{n}$ is the aggregate count of the performance characteristics.

2.6 Analysis of variance (ANOVA)

ANOVA is is employed to know perhaps the processing parameters in the design of the experiment (DOE) have a significant effect on the evaluated materials characteristics. The ANOVA table has also been widely employed to analyze the interactions between processing parameters and the effect of such interactions on the dependent variables (Kilickap et al., 2017). The F-test is used as a measure to investigate the extent of processing parameters controlling the test results. For a $95 \%$ confidence level, if the value of 'Prob $>\mathrm{F}$ ' is less than 0.05 , the processing parameters and interactions are considered significant (Çiçek et al., 2015). Furthermore, a large F-value signifies that its processing parameter has a significant effect on the performance characteristic. In ANOVA, the adjusted correlation coefficient, $\mathrm{R}^{2}$ is used to evaluate the validity of the fitted model. $\mathrm{R}^{2}$ adj measures the percentage of variation explained exclusively by independent processing parameter and interactions which predominantly affect the response variables. Additional, to conclude that the created models fit the performed experiments well, it is desired that the values of $R^{2}$ and $R^{2}$ adj should be high and close to each other (Çiçek et al., 2015; Kilickap et al., 2017)

\subsection{Results and Discussion}

\subsection{RB and HAp characterization analysis}

The phase characteristics of the raw bovine bones (RB) and the synthesized HAp at different sintering temperatures $\left(900,1000\right.$, and $\left.1100{ }^{\circ} \mathrm{C}\right)$ have been presented in Figure 1. The reflected 
patterns noticed on all the samples show the characteristic peaks of calcium phosphate based materials. The noticed characteristic patterns on all the samples are in agreement with several results presented in literature On the RB sample, the low and the broader peak noticed are as a result of the presence of organic residue. On the other hand, the heated samples (900-1100) reflects a sharp and narrower peaks, and as the temperature increases, the reflection becomes narrower and sharper, which is due to the removal of the organic residue and the HAp pure phase formation. This observation can be likened to the increased mechanical properties with increase in sintering temperature, and it is in agreement with the work of Obada et al. (2020), Obada et al. (2021) \& Abifarin (2021).

Figure 2 shows the FTIR characteristic patterns of RB and the sintered HAp at different temperature $\left(900,1000\right.$, and $\left.1100{ }^{\circ} \mathrm{C}\right)$. The reflections show the functional groups peculiar to calcium phosphate materials, which was also validated by the XRD analysis. It is interesting to note that the $\mathrm{OH}$ group band around $3500 \mathrm{~cm}^{-1}$ becomes narrower with increased in sintering temperature, which is associated to the disappearance of absorbed water after heating. The result is in agreement with the work of Abifarin et al. (2019).

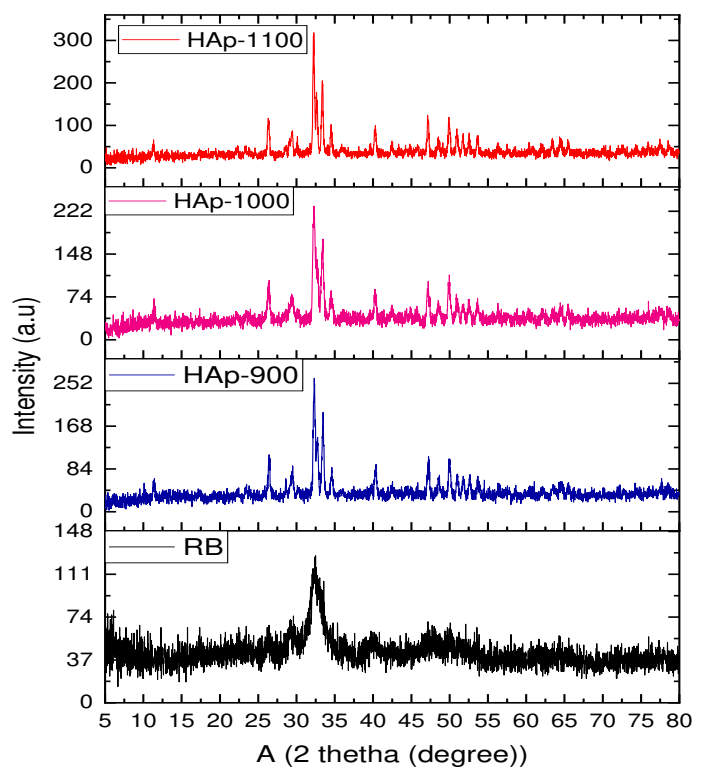

Figure 1: XRD characteristic patterns of RB and HAp at 900,1000 , and $1100{ }^{\circ} \mathrm{C}$ 


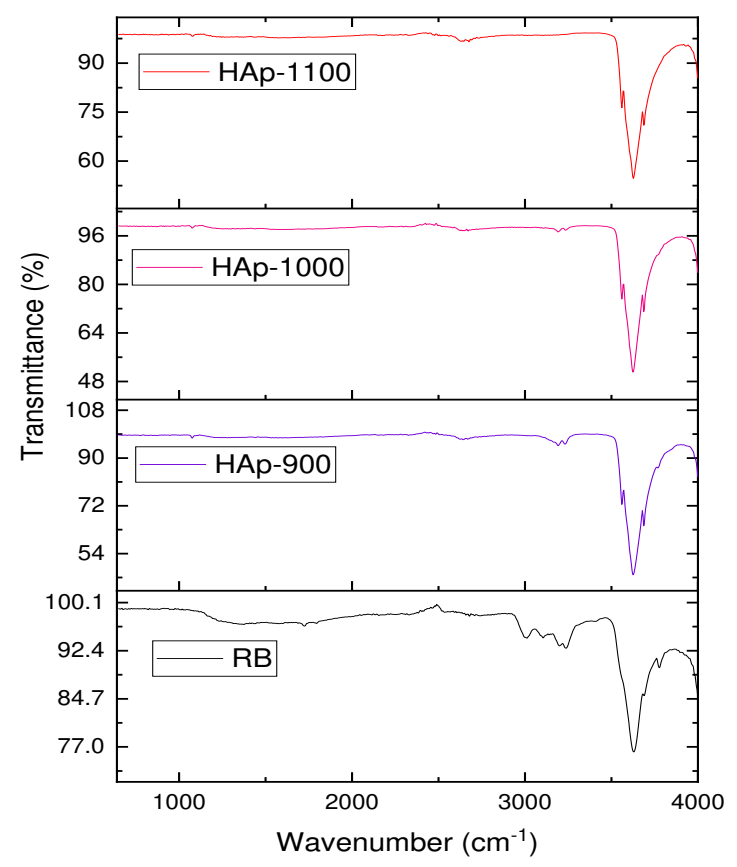

Figure 2: FTIR characteristic patterns of RB and HAp at 900,1000 , and $1100{ }^{\circ} \mathrm{C}$ 3.2 Orthogonal array of the experimental result

Table 2 and 3 reflect the orthogonal array of the experimental mechanical properties and their corresponding Taguchi $\mathrm{S} / \mathrm{N}$ ratios of the processed HAp at different conditions. The S/N ratios and the data analysis were obtained using Minitab 16.

Table 2 highlights of the experimental results of hardness (HV):

\begin{tabular}{llllllll}
\hline Experimental runs & HV1 & HV2 & HV3 & HV4 & HV5 & Mean & S/N ratios \\
\hline 1 & 82.5 & 88.92 & 90.11 & 81.78 & 87.99 & 86.26 & 38.69514 \\
2 & 77 & 72.11 & 78.78 & 68.38 & 70.5 & 73.354 & 37.27154 \\
3 & 72.9 & 66.99 & 71.09 & 68.73 & 65.98 & 69.138 & 36.77668 \\
4 & 89.95 & 96.33 & 89.99 & 92.44 & 88.79 & 91.5 & 39.21751 \\
5 & 75 & 66.89 & 73.44 & 67.67 & 73.27 & 71.254 & 37.02748 \\
6 & 68.89 & 71.2 & 70.93 & 68.87 & 74.22 & 70.822 & 36.99359 \\
7 & 98.77 & 104.89 & 111.22 & 89.88 & 98.56 & 100.664 & 39.99157 \\
8 & 92.88 & 91.11 & 94.39 & 88.78 & 96.45 & 92.722 & 39.33304 \\
9 & 88.78 & 87.65 & 89.99 & 90.37 & 85.79 & 88.516 & 38.93577 \\
\hline
\end{tabular}


Table 3 highlights of the experimental results of compressive strength (MPa):

\begin{tabular}{llllllll}
\hline Experimental runs & CS1 & CS2 & CS3 & CS4 & CS5 & Mean & S/N ratios \\
\hline 1 & 29.87 & 28.77 & 34.42 & 35.65 & 27.88 & 31.318 & 29.79111 \\
2 & 32 & 31.2 & 39.55 & 33.76 & 34.88 & 34.278 & 30.6123 \\
3 & 36.87 & 35.78 & 36.45 & 37.66 & 34.98 & 36.348 & 31.2013 \\
4 & 37.88 & 39.94 & 36.58 & 39.87 & 36.77 & 38.208 & 31.62432 \\
5 & 40.12 & 40.99 & 39.76 & 42.33 & 41 & 40.84 & 32.21562 \\
6 & 43.22 & 41.27 & 46.2 & 39.77 & 45.02 & 43.096 & 32.64942 \\
7 & 42.22 & 44.76 & 41.95 & 44.34 & 45.22 & 43.698 & 32.79666 \\
8 & 44.87 & 45.99 & 47.46 & 49.33 & 45.1 & 46.55 & 33.34226 \\
9 & 49.79 & 59.89 & 60.21 & 54.33 & 50.11 & 54.866 & 34.69787
\end{tabular}

\subsection{Effect of processing parameters on hardness}

The experimental hardness value in Table 2 was analyzed and response table for $\mathrm{S} / \mathrm{N}$ ratios is displayed in Table 4. The processing parameters have been identified from delta statistics in $\mathrm{S} / \mathrm{N}$ ratios response table, and ranks were made according to delta value. The delta statistics is the difference between the highest and the lowest average value of each processing parameters. The first rank reflects the higher value of delta. Table 4 shows that the sintering temperature with a delta value of 1.22 has a close value with compaction load with 1.15 delta value.

Table 4: Response table for hardness $\mathrm{S} / \mathrm{N}$ ratios (larger is better)

\begin{tabular}{lcc}
\hline Processing parameters & Sintering temperature $\left({ }^{\circ} \mathrm{C}\right)$ & Compaction load $(\mathrm{KN})$ \\
\hline Level 1 & 36 & 37.14 \\
Level 2 & 36.1 & 36.19 \\
Level 3 & 37.21 & 35.98 \\
Delta & 1.22 & 1.16 \\
Rank & 1 & 2 \\
\hline
\end{tabular}

The main effects plot for $\mathrm{S} / \mathrm{N}$ ratios of the experimental hardness values was generated from Table 4 as shown in Figure 3. The displayed patterns of the plots for sintering temperature and compaction load indicate that hardness is hugely influenced by change in sintering temperature and compaction load. The plot reveals that increase in sintering temperature increased the hardness $\mathrm{S} / \mathrm{N}$ ratios, while increase in compaction load decreased the hardness $\mathrm{S} / \mathrm{N}$ ratios. The reason for the increasing effect of sintering temperature has been recently reported by Abifarin (2021). The reduction in hardness S/N ratios may be associated with the residual stress generated on the surface of the pellets during compaction, meaning, as the compaction load was increased, much stress was generated on the surface, leading to softer surface of the pelletized HAp. It can 
be concluded from this result that increase in sintering temperature can relieve the stress generated on the surface of the pellets during compaction, but it is safe and economical to employ lesser compaction load which will require lesser sintering temperature to relieve surface stress of the fabricated HAp scaffolds. The results presented in Table 4 and Figure 4 shows that $1100{ }^{\circ} \mathrm{C}$ and $5 \mathrm{KN}$ compaction load are the desired processing parameter levels in order to fabricate HAp scaffold with high hardness property.

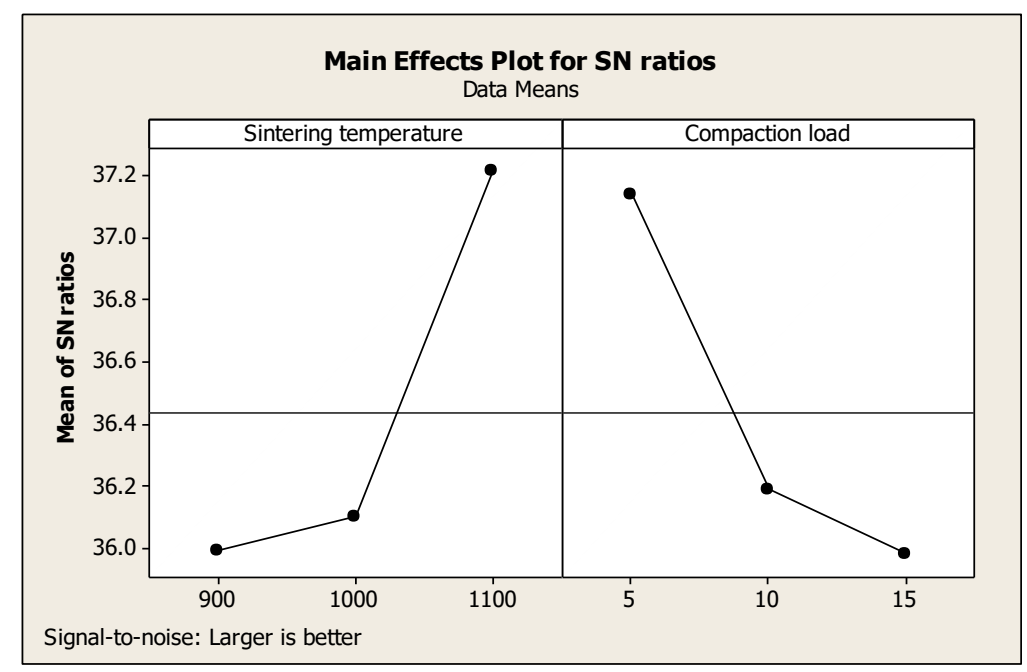

Figure 3: Main effects plots for hardness $\mathrm{S} / \mathrm{N}$ ratios

Sequel to determining the processing parameter levels, analysis of variance (ANOVA) was performed to obtain the percentage contribution of each processing parameter's effect on the hardness value. It can be seen that the compaction load having a contribution of $53.20 \%$ is the most influencing processing parameter affecting HAp hardness value, followed by the sintering temperature having $43.91 \%$, while residual error has $2.89 \%$ which shows that it is insignificant on the HAp hardness value, as it is less than 0.05 (Sudheer et al., 2013; Achuthamenon et al., 2018; Abifarin, 2021). In addition, Table 5 shows that the value of $\mathrm{R}^{2}$ is very high and not close to the value of $\mathrm{R}^{2}$ adj. The variability is explained by the model and affirmed the validity of this model.

Table 5: ANOVA for $\mathrm{S} / \mathrm{N}$ ratio of hardness

\begin{tabular}{lllllll}
\hline Source & DOF & Adj SS & Adj MS & F & Contribution (\%) & Remark \\
\hline Compaction load & 2 & 6.2113 & 3.1056 & 18.41 & 53.20 & Significant \\
Sintering temperature & 2 & 5.1256 & 2.5628 & 15.19 & 43.91 & Significant \\
Residual error & 4 & 0.6749 & 0.1687 & & 2.89 & Insignificant \\
Total & 8 & 12.0117 & 5.8371 & $\mathrm{~S}=0.4108$ & $\mathrm{R}^{2}=94.4 \%$ & $\mathrm{R}^{2}$ Adj $=88.8 \%$ \\
\hline
\end{tabular}

3.4 Effect of processing parameters on compressive strength 
Similar to hardness analysis, the experimental compressive strength shown in Table 3 was analyzed and response table for $\mathrm{S} / \mathrm{N}$ ratios is displayed in Table 6 . The first rank reflects the higher value of delta. Table 4 shows that the sintering temperature has a delta value of 3.08 and compaction load has a delta value of 1.45 .

Table 6: Response table for compressive strength $\mathrm{S} / \mathrm{N}$ ratio (larger is better)

\begin{tabular}{lcc}
\hline Processing parameters & Sintering temperature $\left({ }^{\circ} \mathrm{C}\right)$ & Compaction load $(\mathrm{KN})$ \\
\hline Level 1 & 30.53 & 31.40 \\
Level 2 & 32.16 & 32.06 \\
Level 3 & 33.61 & 32.85 \\
Delta & 3.08 & 1.45 \\
Rank & 1 & 2 \\
\hline
\end{tabular}

The main effects plot for $\mathrm{S} / \mathrm{N}$ ratios of the experimental compressive strength was generated from Table 6 as shown in Figure 4. The displayed patterns of the plots for sintering temperature and compaction load also indicate that compressive strength is significantly influenced by change in sintering temperature and compaction load. The plot reveals that increase in sintering temperature and compaction load increased the compressive strength $\mathrm{S} / \mathrm{N}$ ratios of HAp scaffolds. This observation is similar to the case of HAp hardness values, but compaction load has a reverse effect on compressive strength relative to that of hardness value. The reason for the increase in compressive strength as the compaction load increased could be due to the fact that compaction load increased the bulk density of the HAp scaffolds, which is different from material surface hardness. The result shows that to produce a high compressive strength of HAp scaffolds, higher sintering temperature and compaction load is required, i.e. $1100{ }^{\circ} \mathrm{C}$ and $15 \mathrm{KN}$ compaction load are the desired processing parameter levels to have high compressive strength HAp scaffold.

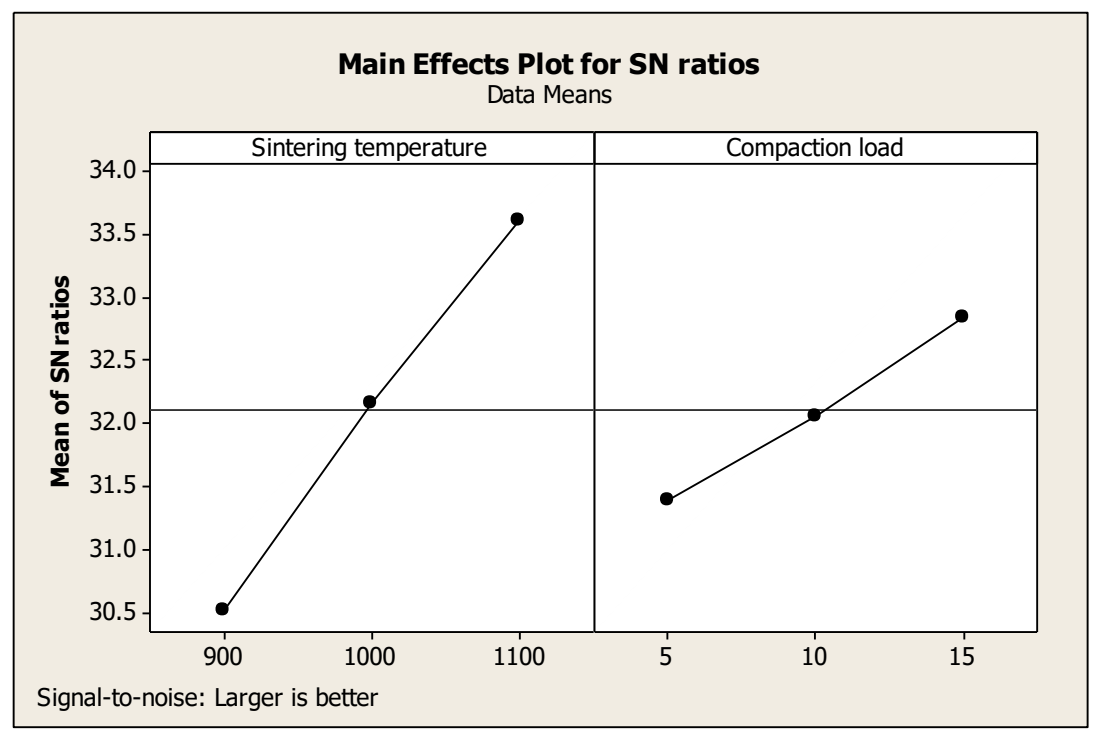

Figure 4: Main effects plots for compressive strength $\mathrm{S} / \mathrm{N}$ ratios 
In order to obtain the percentage of contribution of each processing parameter's effect on HAp compressive strength, ANOVA was performed, as it is displayed in Table 7. As it was noticed on hardness analysis, compaction load having contribution of $81.18 \%$ is the most influencing processing parameter affecting the compressive strength of the fabricated HAp scaffold, followed by the sintering temperature having $17.95 \%$, but residual error was insignificant, having $0.87 \%$. In addition, Table 5 shows high values of $\mathrm{R}^{2}$ and $\mathrm{R}^{2}$ adj, and are comparable. This shows the goodness of fit of the model.

Table 7: ANOVA for S/N ratio of compressive strength

\begin{tabular}{lllllll}
\hline Source & DOF & Adj SS & Adj MS & F & Contribution (\%) & Remark \\
\hline Compaction pressure & 2 & 14.2212 & 7.11062 & 93.11 & 81.18 & Significant \\
Sintering temperature & 2 & 3.14400 & 1.57200 & 20.58 & 17.95 & Significant \\
Residual error & 4 & 0.30550 & 0.07637 & & 0.87 & Insignificant \\
Total & 8 & 17.6707 & 8.75899 & $\mathrm{~S}=0.2764$ & $\mathrm{R}^{2}=98.3 \%$ & $\mathrm{R}^{2}$ Adj $=96.5 \%$ \\
\hline
\end{tabular}

\subsection{Grey relational analysis for the multiple performance characteristics}

It is important to determine the optimum processing parameter levels for the fabrication of HAp scaffolds having high hardness value and high compressive strength. The results displayed under the effect of processing parameters on HAp hardness value and compressive strength showed that $1100{ }^{\circ} \mathrm{C}$ sintering temperature is required to produce mechanically enhanced HAp, but for compaction load, $5 \mathrm{KN}$ is required for high hardness value, while $15 \mathrm{KN}$ is required for high compressive strength. Since, there must be one parameter level to be considered for compaction load, it is therefore important to employ grey relational analysis (GRA) for optimum processing parameters.

GRA is principally utilized to address issues containing a restricted arrangement of information. It is commonly used to have a full grasp of unsure frameworks with no highly contrasting arrangement. In grey system, black means having no data and white connotes having all data (Julong, 1989; Abifarin, 2021).

The pre-processing of data with grey relational generation was performed on the experimental mechanical properties of the responses in Table 2 and 3, in particular, hardness and compressive strength. The reference sequence of the responses within 0 to 1 was gotten by normalizing the data using Equation (2). Next, the deviation sequences were calculated using Equation (3). Table 8 shows the reference and deviation sequences acquired after data pre-processing.

After getting deviation sequences, the GRC $\left(\xi_{i}(k)\right)$ for each response value was determined using Equation (4). At last, the average of the GRCs was done to get the grey relational grade (GRG). As recorded in Table 9, the processed values of GRGs were used to get the corresponding $\mathrm{S} / \mathrm{N}$ ratios. A higher value of $\mathrm{S} / \mathrm{N}$ proportion is helpful and shows that the experimental mechanical properties lies near the ideal normalized value of GRG (Wojciechowski et al., 2018). Figure 5 displays the plot of $\mathrm{GRG}$ versus $\mathrm{S} / \mathrm{N}$ ratios. It shows that the last experimental mechanical properties run has the most noteworthy $\mathrm{S} / \mathrm{N}$ ratio. In like manner, the 
principal rank was appointed to the last experimental run. The significance of the GRG, with plot of S/N ratios in Figure 5, additionally supplements the above discussion.

After ranking has been done, a response table for the GRG was brought out. The GRG of each factor at the picked level was chosen and found the average value to produce the mean of GRG for singular elements. For example, the processing parameter sintering temperature at level 3 in the seventh, eighth, and ninth runs of the experiment. The corresponding GRG values from Table 9 were used for estimation as displayed in Equation (5).

Table 8: Reference and deviation sequence after pre-processing of data

\begin{tabular}{lllll}
\hline \multirow{2}{*}{ Experimental run } & \multicolumn{2}{c}{ Reference Sequence, $x_{\mathrm{i}}$} & \multicolumn{2}{c}{ Deviation Sequence, $\Delta_{\mathrm{oi}}$} \\
\cline { 2 - 5 } & Mean HV & Mean CS & Mean HV & Mean CS \\
\hline 1 & 0.54311 & 0 & 0.456892723 & 1 \\
2 & 0.13373 & 0.1257 & 0.866269111 & 0.874299304 \\
3 & 0 & 0.21361 & 1 & 0.786393749 \\
4 & 0.70932 & 0.29259 & 0.290680708 & 0.707406149 \\
5 & 0.06712 & 0.40437 & 0.932880797 & 0.595634449 \\
6 & 0.05342 & 0.50017 & 0.946583772 & 0.499830134 \\
7 & 1 & 0.52573 & 0 & 0.47426533 \\
8 & 0.74808 & 0.64685 & 0.251919051 & 0.353151011 \\
9 & 0.61467 & 1 & 0.385332741 & 0 \\
\hline
\end{tabular}

Table 9: Rank of grey relational grade (GRG) with $\mathrm{S} / \mathrm{N}$ ratios.

\begin{tabular}{llllll}
\hline & \multicolumn{2}{l}{ Grey Relational Coefficient, $\varepsilon_{\mathrm{i}}(\mathrm{k})$} & & & \\
\cline { 2 - 5 } Experimental run & Mean HV & Mean CS & GRG, $\gamma_{\mathrm{i}}$ & S/N Ratio of GRG & Rank \\
\hline 1 & 0.522525 & 0.333333 & 0.427928973 & -7.372566168 & 5 \\
2 & 0.36596 & 0.363822 & 0.36489094 & -8.756738389 & 8 \\
3 & 0.333333 & 0.388683 & 0.361008407 & -8.849653685 & 9 \\
4 & 0.632367 & 0.414111 & 0.523238686 & -5.626003079 & 4 \\
5 & 0.348947 & 0.456357 & 0.402651985 & -7.90140312 & 7 \\
6 & 0.345642 & 0.500085 & 0.422863436 & -7.475997307 & 6 \\
7 & 1 & 0.513207 & 0.756603609 & -2.422631828 & 2 \\
8 & 0.664965 & 0.586063 & 0.625513957 & -4.075259903 & 3 \\
9 & 0.564759 & 1 & 0.782379707 & -2.131648453 & 1 \\
\hline
\end{tabular}




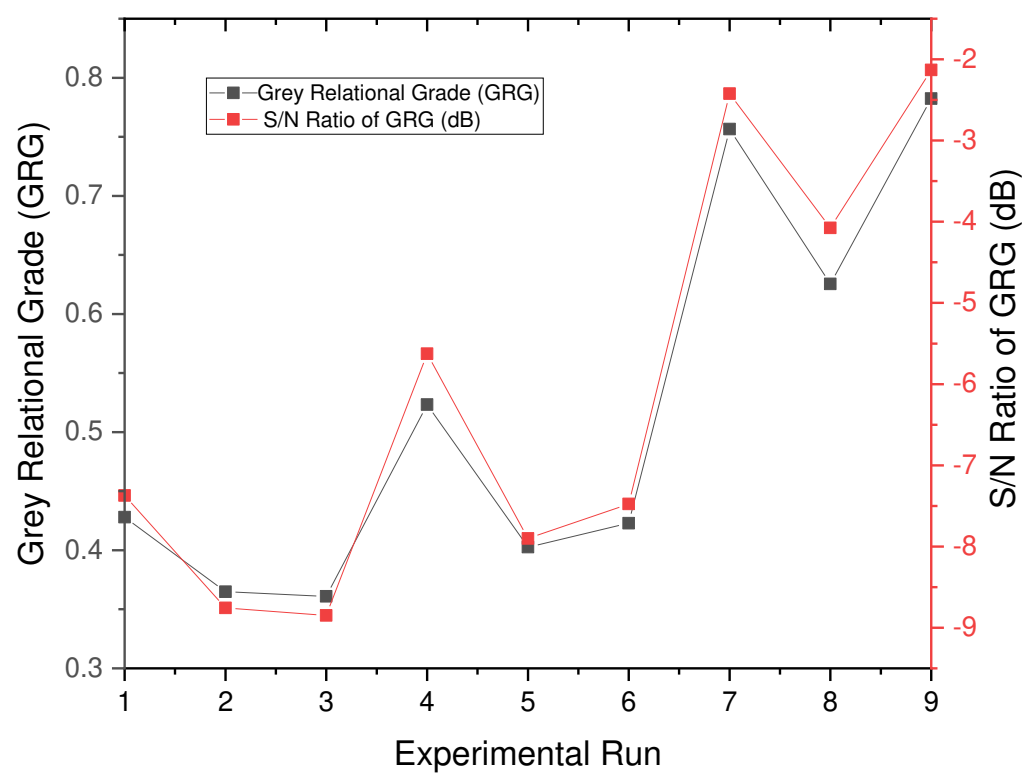

Figure 5: GRG vs S/N Ratio Plot

The mean of chosen GRGs was determined by employing the method above to make the response table displayed in Table 10. The grades in the response table is the proportion of the connection between the reference sequences and equivalence sequence of GRA. Higher values of the mean of GRGs show a solid relationship (Kasemsiri et al., 2017). Consequently, from the response table of GRGs in Table 10, it is feasible to get the combination of the process parameters that boost overall mechanical properties. From Table 10, the highest grey relational grades exist at sintering temperature at level 3 , and compaction load at level 1 . Thus, to finish up, the optimal processing parameters for the fabrication of mechanically enhanced HAp scaffold are the sintering temperature at $1100{ }^{\circ} \mathrm{C}$ and compaction load at $5 \mathrm{KN}$.

Sintering temperature (level 3) $=\frac{0.7566+0.6255+0.7824}{3}=0.7215$

Table 10: Response table for means (larger is better)

\begin{tabular}{llc}
\hline Processing parameters & Sintering temperature $\left({ }^{\circ} \mathrm{C}\right)$ & Compaction load $(\mathrm{KN})$ \\
\hline Level 1 & 0.3846 & 0.5693 \\
Level 2 & 0.4496 & 0.4644 \\
Level 3 & 0.7215 & 0.5221 \\
Delta & 0.3369 & 0.1049 \\
Rank & 1 & 2 \\
\hline
\end{tabular}

Mean of GRG $=0.5186$ 


\subsection{ANOVA for GRG}

To examine the significance and percentage of contribution of each processing parameter on the multiple mechanical properties of HAp, an ANOVA was performed for the grey relational grade at a 95\% confidence level. Considering the two responses (hardness and compressive strength), Table 11 shows that the compaction load has the most noteworthy impact, of $90.15 \%$, on the GRG, followed by the sintering temperature, with $7.79 \%$, but residual error is insignificant, with $2.06 \%$. The high $\mathrm{R}$ values imply the goodness of fit of the model developed.

Table 11: ANOVA for GRG

\begin{tabular}{lllllll}
\hline Source & DOF & Adj SS & Adj MS & F & Contribution (\%) & Remark \\
\hline Compaction pressure & 2 & 0.191654 & 0.095827 & 43.79 & 90.15 & Significant \\
Sintering temperature & 2 & 0.016563 & 0.008282 & 3.78 & 7.79 & Significant \\
Residual error & 4 & 0.008753 & 0.002188 & & 2.06 & Insignificant \\
Total & 8 & 0.216970 & 0.106297 & $\mathrm{~S}=0.04678$ & $\mathrm{R}^{2}=96.0 \%$ & $\mathrm{R}^{2}{ }_{\text {Adj }}=91.9 \%$ \\
\hline
\end{tabular}

\subsection{Confirmation analysis}

After the knowing the optimal processing parameter levels, the last step is to predict the response, which is shown in Equation 7: (Ross, 1996; Abifarin, 2021; Awodi et al., 2021)

$\gamma_{\text {predicted }}=\gamma_{m}+\sum_{i=1}^{q} \gamma_{0}-\gamma_{m}$

Where $\gamma_{0}$ is the maximum average value GRG at the optimal processing parameter level and $\gamma_{m}$ implies the average of GRG. $q$ is the number of the processing parameters.

From Equation 7 and Table 10, the grey relational grade was predicted using the optimal processing parameter levels. The predicted GRG is 0.7722, compared with the experimental values, which is 0.7824 , and it is the average of experimental numbers 7,8 , and 9 .

Confidence interval $(\mathrm{CI})$ is used in Equation 8 to determine the closeness of the experimental GRG value and the predicted GRG value (Taguchi \& Phadke, 1989; Abifarin, 2021):

$C I=\sqrt{F_{\alpha}\left(1, f_{e}\right) V_{e}\left[\frac{1}{\eta_{e f f}}+\frac{1}{R}\right]}$

$F_{\alpha}\left(1, f_{e}\right)=\mathrm{F}$ ratio required for $\alpha ; \alpha=$ risk; $f_{e}=$ DOF of error; $\mathrm{V}_{\mathrm{e}}=$ variance of error; $\eta_{e f f}=$ effective number of replications, which is the Equation 9 below:

$\eta_{\text {eff }}=\frac{N}{1+(\text { total DOF of control factors })}$

$\mathrm{R}=$ number of replications when the experiment is carried out for confirmation; $\mathrm{N}=$ total number of experiments.

Therefore; 
$\mathrm{V}_{\mathrm{e}}=0.002188 ; \mathrm{f}_{\mathrm{e}}=4$

Total DOF of control factors $=4$

$\mathrm{R}=1, \mathrm{~N}=9$

$\alpha=0.5$ (95\% confidence interval)

$F_{0.5}(1,4)=7.71$ (tabulated values from the F-Tables)

$\eta_{\text {eff }}=\frac{9}{1+4}=1.8$

$C I=\sqrt{7.71 \times 0.002188\left[\frac{1}{1.8}+\frac{1}{1}\right]}= \pm 0.162$

$95 \%$ confidence interval of the predicted optimal grey relational grade is given in Equation 10, as posited by Abifarin (2021):

$\gamma_{\text {predicted }}-C I<\gamma_{\text {experimental }}<\gamma_{\text {predicted }}+C I$

$0.6102<\gamma_{\text {experimental }}<0.9342$

The confidence interval reveals that the experimental grey relational grade, 0.7824 is close to the predicted optimal grey relational grade, which authenticates the efficacy of the optimal processing parameter levels for the fabrication of mechanically enhanced HAp scaffold.

\subsection{Conclusions}

Fabrication of mechanically improved HAp scaffold assisted by Taguchi-grey relational analysis has been done. XRD and FTIR characteristic patterns of RB and HAp sintered at 900, 1000, and $1100{ }^{\circ} \mathrm{C}$ confirmed calcium phosphate based materials. The result also revealed that as the temperature increased, the prominent characteristic peak of pure HAp became narrower, which suggests the increase in crystallinity of pure phase HAp. Taguchi design analysis on individual mechanical properties (hardness and compressive strength) revealed that $1100{ }^{\circ} \mathrm{C}$ was the optimal sintering temperature for individual hardness and compressive strength, but there was disparity on compaction load processing parameter level ( $5 \mathrm{KN}$ for high hardness value, while 15 $\mathrm{K}$ was required for high compressive strength. However, Taguchi-grey relational analysis assisted in determining a common optimal processing parameter levels for high hardness and compressive strength. It was revealed that the optimal processing parameter levels for the fabrication of mechanically enhanced HAp scaffold are the sintering temperature at $1100{ }^{\circ} \mathrm{C}$ and compaction load at $5 \mathrm{KN}$. It is noteworthy to highlight that this study revealed a very high significance level $(90.15 \%)$ of compaction load in the fabrication of mechanically enhanced HAp scaffold compared to sintering temperature having a contribution of $7.79 \%$. Confirmation analysis proved that the experimental grey relational grade $(0.7824)$ is within $95 \%$ confidence interval. 


\section{Declaration:}

Funding: This research did not receive any funding

Conflicts of interest/Competing interests: On behalf of the authors, the corresponding author declares no conflict of interest

Availability of data and material: Not applicable

Code availability: Not applicable

Ethics approval: Not applicable

Consent to participate: Not applicable

Consent for publication: Not applicable

\section{References:}

Abifarin, J. K. (2021). Taguchi grey relational analysis on the mechanical properties of natural hydroxyapatite: effect of sintering parameters. The International Journal of Advanced Manufacturing Technology, 1-9.

Abifarin, J. K., Obada, D. O., Dauda, E. T., \& Dodoo-Arhin, D. (2019). Experimental data on the characterization of hydroxyapatite synthesized from biowastes. Data in brief, 26, 104485.

Achuthamenon Sylajakumari, P., Ramakrishnasamy, R., \& Palaniappan, G. (2018). Taguchi grey relational analysis for multi-response optimization of wear in co-continuous composite. Materials, 11(9), 1743.

Achuthamenon Sylajakumari, P., Ramakrishnasamy, R., \& Palaniappan, G. (2018). Taguchi grey relational analysis for multi-response optimization of wear in co-continuous composite. Materials, 11(9), 1743.

Adeogun, A. I., Ofudje, A. E., Idowu, M. A., \& Kareem, S. O., 2018. Facile Development of Nano Size Calcium Hydroxyapatite Based Ceramic from Eggshells: Synthesis and Characterization. Waste and biomass valorization, 9(8), 1469-1473.

Awodi, E., Ishiaku, U. S., Yakubu, M. K., \& Abifarin, J. K. (2021). Experimentally Predicted Optimum Processing Parameters Assisted by Numerical Analysis on the Multiphysicomechanical Characteristics of Coir Fiber Reinforced Recycled High Density Polyethylene Composites.

Çiçek, A., Kıvak, T., \& Ekici, E. (2015). Optimization of drilling parameters using Taguchi technique and response surface methodology (RSM) in drilling of AISI 304 steel with cryogenically treated HSS drills. Journal of Intelligent Manufacturing, 26(2), 295-305.

Julong, D. (1989). Introduction to grey system theory. The Journal of grey system, 1(1), 1-24.

Kasemsiri, P., Dulsang, N., Pongsa, U., Hiziroglu, S., \& Chindaprasirt, P. (2017). Optimization of biodegradable foam composites from cassava starch, oil palm fiber, chitosan and palm oil using Taguchi method and grey relational analysis. Journal of Polymers and the Environment, 25(2), 378-390. 
Kilickap, E., Yardimeden, A., \& Çelik, Y. H. (2017). Mathematical modelling and optimization of cutting force, tool wear and surface roughness by using artificial neural network and response surface methodology in milling of Ti-6242S. Applied Sciences, 7(10), 1064.

Lin, C. L. (2004). Use of the Taguchi method and grey relational analysis to optimize turning operations with multiple performance characteristics. Materials and manufacturing processes, 19(2), 209-220.

Manoharan, S., Krishnaraj, V., Vijay, R., Singaravelu, D. L., \& Suresha, B. (2017). 3. Development and characterization of novel fiber reinforced hybrid friction composites. In Green Composites (pp. 69-114). De Gruyter.

Niakan, A., Ramesh, S., Ganesan, P., Tan, C. Y., Purbolaksono, J., Chandran, H., \& Teng, W. D. (2015). Sintering behaviour of natural porous hydroxyapatite derived from bovine bone. Ceramics International, 41(2), 3024-3029..

Obada, D. O., Dauda, E. T., Abifarin, J. K., Bansod, N. D., \& Dodoo-Arhin, D. (2021). Mechanical measurements of pure and kaolin reinforced hydroxyapatite-derived scaffolds: A comparative study. Materials Today: Proceedings, 38, 2295-2300.

Obada, D. O., Dauda, E. T., Abifarin, J. K., Dodoo-Arhin, D., \& Bansod, N. D. (2020). Mechanical properties of natural hydroxyapatite using low cold compaction pressure: Effect of sintering temperature. Materials Chemistry and Physics, 239, 122099.

Pervez, M., Shafiq, F., Sarwar, Z., Jilani, M. M., \& Cai, Y. (2018). Multi-response optimization of resin finishing by using a taguchi-based grey relational analysis. Materials, 11(3), 426.

Prasanth, A. S., \& Ramesh, R. (2017). Investigation of surface roughness and tool wear in end milling of Al7075-SiC Co-continuous composite. In Materials Design and Applications (pp. 315-327). Springer, Cham.

Prasanth, A. S., Ramakrishnasamy, R., \& Palaniappan, G. (2018). Taguchi grey relational analysis for multi-response optimization of wear in co-continuous composite. Materials, 11(9), 1743.

Puh, F., Jurkovic, Z., Perinic, M., Brezocnik, M., \& Buljan, S. (2016). Optimization of machining parameters for turning operation with multiple quality characteristics using Grey relational analysis. Tehnički vjesnik, 23(2), 377-382.

Ross, P. J. (1996). Taguchi techniques for quality engineering: loss function, orthogonal experiments, parameter and tolerance design.

Sudheer, M., Prabhu, R., Raju, K., \& Bhat, T. (2013). Modeling and analysis for wear performance in dry sliding of Epoxy/Glass/PTW composites using full factorial techniques. International Scholarly Research Notices, 2013.

Taguchi, G., \& Phadke, M. S. (1989). Quality engineering through design optimization. In Quality Control, Robust Design, and the Taguchi Method (pp. 77-96). Springer, Boston, MA.

Wojciechowski, S., Maruda, R. W., Krolczyk, G. M., \& Niesłony, P. (2018). Application of signal to noise ratio and grey relational analysis to minimize forces and vibrations during precise ball end milling. Precision Engineering, 51, 582-596.

Zhang, D., Chen, M., Wu, S., Liu, J., \& Amirkhanian, S. (2017). Analysis of the relationships between waste cooking oil qualities and rejuvenated asphalt properties. Materials, 10(5), 508. 